Article

\title{
Green Synthesis Method and Application of NaP Zeolite Prepared by Coal Gasification Coarse Slag from Ningdong, China
}

\author{
Wenxin Ji ${ }^{1,2, *}$, Shiyue Zhang ${ }^{1}$, Pengde Zhao ${ }^{1}$, Shasha Zhang ${ }^{2}$, Ning Feng ${ }^{1}$, Liping Lan ${ }^{2}$, \\ Xiaoguang Zhang ${ }^{2, *}$, Yonggang Sun ${ }^{1,2}$, Yuanyuan $\mathrm{Li}^{1,2}$ and Yulong Ma ${ }^{1,2}$ \\ 1 State Key Laboratory of High-efficiency Utilization of Coal and Green Chemical Engineering, \\ Ningxia University, Yinchuan 750021, China \\ 2 College of Chemistry and Chemical Engineering, Ningxia University, Yinchuan 750021, China \\ * Correspondence: jwx@nxu.edu.cn (W.J.); ndzhangxg@126.com (X.Z.); Tel.: +86-135-1957-9989 (W.J.); \\ +86-139-9521-8798 (X.Z.)
}

Received: 17 March 2020; Accepted: 7 April 2020; Published: 13 April 2020

\begin{abstract}
In view of the current and urgent environmental protection needs, the use of industrial solid waste in China's Ningdong is becoming more and more important. In this paper, NaP zeolite with good physical properties is synthesized by using coal gasification coarse slag (CGCS) as the raw material, without the addition of a silicon and aluminum source, without the addition of a template agent, and without high-temperature calcination. Add a small amount of $\mathrm{NaOH}$ and deionized water to the CGCS to adjust the molar ratio to $\mathrm{SiO}_{2}: \mathrm{Al}_{2} \mathrm{O}_{3}: \mathrm{Na}_{2} \mathrm{O}: \mathrm{H}_{2} \mathrm{O}=5.2: 1.0: 5.0: 100$. The effects of aging time, crystallization temperature, and crystallization time parameters on synthetic zeolite were studied. The raw materials and the obtained zeolite were tested by XRF, XRD, SEM, FT-IR, TG-DSC, $\mathrm{BET}$, and other technologies. The results show that the specific surface area of the synthesized NaP zeolite can reach $161.06 \mathrm{~m}^{2} / \mathrm{g}$, which has the characteristics of large specific surface area, regular morphology, and high crystallinity. We obtained $\mathrm{NaP}$ zeolite through a simple and low-cost synthesis method. The synthesized $\mathrm{NaP}$ zeolite was used to simulate the removal of ammonia nitrogen in wastewater, and the optimal removal rate was $92.67 \%$. Among them, $\mathrm{Na}^{+}$plays an important role in the synthesis of $\mathrm{NaP}$ zeolite and ion exchange with $\mathrm{NH}_{4}{ }^{+}$. Our research provides new ideas for solving the large-scale accumulation of CGCS and treating ammonia nitrogen in industrial wastewater. Thus, it is a promising green environmental protection and "treating waste by waste" route.
\end{abstract}

Keywords: coal gasification coarse slag; $\mathrm{NaP}$ zeolite; ammonia nitrogen; green environmental

\section{Introduction}

With the huge impact of global climate change on the human living environment, the clean and efficient use of coal is particularly important. At present, China's clean coal mainly uses coal gasification and other technologies. Coal gasification slag (CGS) is the solid waste generated by the entrained-flow coal gasification technology. According to different pathways of formation, it consists of two forms (coarse slag and fine slag). Coal gasification technology has been widely used for the demand for energy, but the problem of solid waste and water pollution is becoming more and more serious [1,2]. Ningdong energy and chemical base is one of the most advanced bases for developing clean coal technology in China. In 2018, the base generated nearly 8 million tons of CGS [3]. At present, there is no good treatment method, and it can only be landfilled after high-standard anti-seepage treatment on the ground, which is quite different from the systematic utilization of fly ash [4-8]. This treatment not only occupies land resources, causes enormous environmental pressure, but also brings 
high transportation and processing costs to the enterprise. Therefore, it is especially important to realize the "zero emission" [9] of coal gasification technology and to find ways to recycle CGS.

At present, there are many researches on the resource utilization of fly ash and slag in the world $[7,8,10]$. However, since the CGS is obtained in a high-pressure vaporization furnace under a reducing atmosphere $\left(\mathrm{CO}, \mathrm{H}_{2}\right)$ and $1400-1500^{\circ} \mathrm{C}$, its structure and composition are greatly different from those of fly ash and slag [3,5,9]. Therefore, it is difficult to realize the utilization of CGS by the same method. In this new field, only a few researchers have studied the application of CGS in porous materials, but they have not paid much attention to its resource utilization [11-14]. Although they have also synthesized excellent porous materials, their preparation process is still considered to have shortcomings such as high production cost, complicated process, easy secondary pollution and high energy consumption. At present, there are many methods for treating wastewater using solid waste, but they cannot be applied on a large scale due to the "cost and system integration" problem. Therefore, it is especially important to study a resource-based gasifier slag technology with low cost, simple process, low energy consumption, minimal secondary pollution and high system integration, and this technology will have high application value in the future.

This study is based on China Ningdong coal gasification coarse slag (CGCS) $[3,15,16]$. We hope to find a feasible way for the utilization of CGCS with the increasingly severe environmental pressure. $\mathrm{NaP}$ zeolite is synthesized by a low-cost green template-free method (the best process is shown in Figure 1): CGCS is used as the raw material, no additional silicon-aluminum source is required, and no high-temperature calcination is required. Add a small amount of sodium hydroxide and deionized water and mix well, then age and crystallize. The effects of different molar ratios, aging time, crystallization temperature and other parameters on the synthesis of zeolite were investigated. The crystal type, morphology, specific surface area, and pore structure of the product were analyzed and tested by a characterization method, whereby it was found that the specific surface area of the synthesized NaP zeolite was up to $161.06 \mathrm{~m}^{2} / \mathrm{g}$. The prepared $\mathrm{NaP}$ zeolite was used to remove ammonia nitrogen from simulated wastewater. The effect of $\mathrm{pH}$, adsorption time, and adsorbent dosage on the removal efficiency was briefly studied, and the optimum removal rate was $92.67 \%$. This research can realize the in-situ treatment and utilization of waste generated by the factory, avoid the transportation cost, and realize "treating waste by waste", which provides a new way for the recycling of CGCS and the treatment of ammonia nitrogen in industrial wastewater.

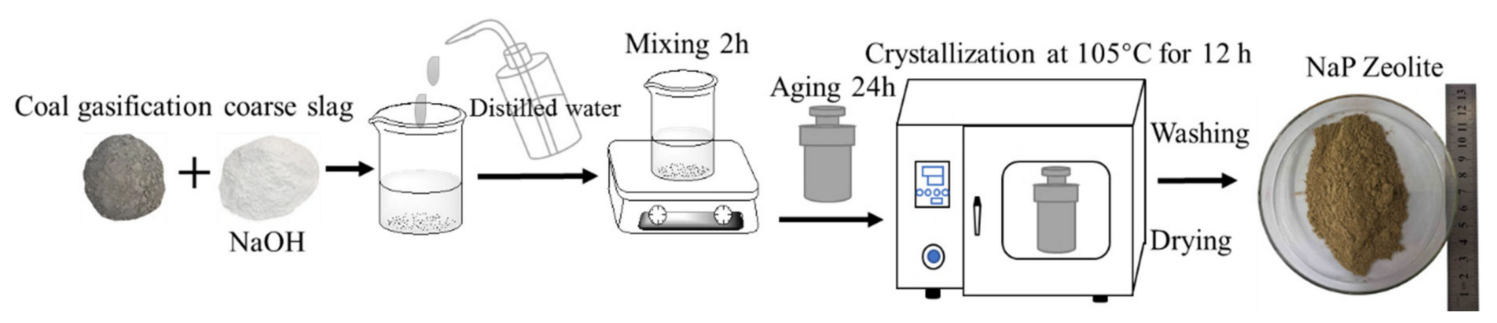

Figure 1. Schematic diagram of preparation process of $\mathrm{NaP}$ zeolite.

\section{Experimental}

\subsection{CGCS and Reagent}

The CGCS used in this study came from Ningdong Energy and Chemical Industry Base (Yinchuan, China). Chemical reagents: sodium hydroxide, non-hydrated sodium metasilicate, aluminum powder, hydrochloric acid, sodium potassium tartrate, anhydrous ammonium chloride are of analytical grade (purity $>99.5 \%$ ), purchased from Shanghai (Sinopharm Chemical Reagent Co., Ltd, Shanghai, China). Among them, anhydrous sodium metasilicate and aluminum powder were only used to study the effect of $\mathrm{SiO}_{2} / \mathrm{Na}_{2} \mathrm{O}$ and $\mathrm{SiO}_{2} / \mathrm{Al}_{2} \mathrm{O}_{3}$ on the performance of synthetic zeolite. Hydrochloric acid, sodium potassium tartrate, and anhydrous ammonium chloride were used for the ammonia nitrogen adsorption experiment. Prepared before the use of Nessler's reagent, purchased from Shanghai 
(Maclean Biochemical Technology Co., Ltd, Shanghai, China). Dissolve anhydrous ammonium chloride in deionized water to obtain simulated ammonia nitrogen wastewater.

\subsection{Synthesis of NaP Zeolite}

Amorphous silica and alumina in CGCS are used as the silicon source aluminum source, and zeolite is synthesized without adding any template and without high temperature calcination. Grinding and sieving the raw material select a part with a particle size of less than $75 \mu \mathrm{m}$. Add $0.33 \mathrm{~g} \mathrm{NaOH}$ and $3 \mathrm{~mL}$ deionized water to $1 \mathrm{~g}$ CGCS to adjust $\mathrm{SiO}_{2}: \mathrm{Al}_{2} \mathrm{O}_{3}: \mathrm{Na}_{2} \mathrm{O}: \mathrm{H}_{2} \mathrm{O}=5.2: 1.0: 5.0: 100$. The mixture was then transferred to a $100 \mathrm{~mL}$ stainless steel autoclave (polytetrafluoroethylene lined) and aged for $6-72 \mathrm{~h}$ at room temperature. The autoclave was sealed and placed in an oven at $80-130{ }^{\circ} \mathrm{C}$ for $6-72 \mathrm{~h}$. Rinse with distilled water until neutral, dry at $105^{\circ} \mathrm{C}$ for $6 \mathrm{~h}$, and store under seal.

\subsection{Sample Characterization}

X-ray fluorescence spectroscopy (XRF) studied the chemical composition of CGCS by using a S2 Ranger type (Bruker, Karlsruhe, Baden-Wurttemberg, Germany) spectrometer. The crystal phase of the solid product was subjected to X-ray diffraction (XRD) studies using a D8 advance type diffractometer (Bruker, Karlsruhe, Baden-Wurttemberg, Germany). The $\mathrm{CuK} \alpha$ radiation source operates at voltages of $40 \mathrm{kV}$ and $40 \mathrm{~mA}$. The $2 \theta$ range was $5-50^{\circ}$ and the scan rate is $2^{\circ} / \mathrm{min}$. The scanning electron microscopy (SEM) was carried out by using JSM-7500F (JEOL, Tokyo, Japan) to study the morphology and structure of the composite materials. Fourier transform infrared spectroscopy (FT-IR) analysis in a Spectrum Two type (PerkinElmer, Waltham, MA, USA) spectrometer using KBr tablets. Thermogravimetric (TG)/differential scanning calorimetry (DSC) analysis was performed using a STA 449 F5 (Netzsch, Nuremberg, Bavaria, Germany) synchronous thermal analyzer with a heating rate of $10^{\circ} \mathrm{C} / \mathrm{min}$. The $\mathrm{N}_{2}$ adsorption-desorption isotherm curve was obtained at $-196{ }^{\circ} \mathrm{C}$ using an ASAP2020 physical adsorption analyzer (Micromeritics, Norcross, GA, USA). The specific surface area was determined by BET equation, and the pore size distribution was calculated by $\mathrm{N}_{2}$-DFT model. Prior to this analysis, the samples were evacuated at $200{ }^{\circ} \mathrm{C}$ for $2 \mathrm{~h}$.

\subsection{Ammonia Nitrogen Removal Experiment}

The $\mathrm{NaP}$ zeolite washed to neutrality (aged for $24 \mathrm{~h}$ and crystallized at $105^{\circ} \mathrm{C}$ for $12 \mathrm{~h}$ ) was selected for ammonia nitrogen adsorption. The zeolite was added to a simulated ammonia nitrogen solution having a volume of $100 \mathrm{~mL}$ and a concentration of $100 \mathrm{mg} / \mathrm{L}$ (temperature: $25^{\circ} \mathrm{C}$, oscillation frequency: $180 \mathrm{r} / \mathrm{min}$ ). The effects of adsorbent dosage, solution $\mathrm{pH}$ and adsorption time on ammonia nitrogen removal rate and adsorption capacity were studied. The mixture was centrifuged and filtered under different conditions. The ammonia nitrogen concentration in water was determined by Nessler's reagent method according to the Chinese National Standard (HJ 535-2009) [17], and the ultraviolet-visible spectrophotometer (UV-1800, Shimadzu, Tokyo, Japan) was at a wavelength of $420 \mathrm{~nm}$. The formula for ammonia nitrogen removal rate and adsorption is as follows:

$$
\begin{aligned}
& \mathrm{T}(\%)=\frac{\mathrm{C}_{0}-\mathrm{C}_{\mathrm{e}}}{\mathrm{C}_{0}} \times 100 \% \\
& \mathrm{Q}(\mathrm{mg} / \mathrm{g})=\frac{\mathrm{C}_{0}-\mathrm{C}_{\mathrm{e}}}{\mathrm{M}} \times \mathrm{V}
\end{aligned}
$$

where $\mathrm{T}$ is the removal rate, $\mathrm{Q}$ is the adsorption amount, $\mathrm{C}_{0}(\mathrm{mg} / \mathrm{L})$ is the initial ammonia nitrogen concentration, $C_{e}(\mathrm{mg} / \mathrm{L})$ is the equilibrium ammonia nitrogen concentration, $\mathrm{M}(\mathrm{g})$ is the amount of adsorbent added, and $\mathrm{V}(\mathrm{L})$ is the volume of ammonia nitrogen wastewater. 


\subsubsection{Influence of Adsorbent Dosage}

Adding $0.5-40 \mathrm{~g} / \mathrm{L} \mathrm{NaP}$ zeolite to the solution, adjusting the $\mathrm{pH}$ of the solution to 7 and the adsorption time of $180 \mathrm{~min}$, the effect of adsorbent dosage on the ammonia nitrogen removal rate was studied. The removal rate and adsorption amount are calculated by using Equations (1) and (2).

\subsubsection{Influence of $\mathrm{pH}$}

In order to study the effect of $\mathrm{pH}$ on ammonia nitrogen removal rate, $1 \mathrm{M} \mathrm{NaOH}$ and $1 \mathrm{M} \mathrm{HCl}$ were added to adjust the solution $\mathrm{pH}$ to $3-10$. The previously determined $20 \mathrm{~g} / \mathrm{L} \mathrm{NaP}$ zeolite was added and the adsorption time was $180 \mathrm{~min}$. Equation (1) was used to calculate the ammonia nitrogen removal rate at different $\mathrm{pH}$ values.

\subsubsection{Influence of Adsorption Time}

Twelve time points were selected within 5-480 min to study the effect of adsorption time on ammonia nitrogen removal rate. The previously determined $20 \mathrm{~g} / \mathrm{L} \mathrm{NaP}$ zeolite was added to adjust the solution $\mathrm{pH}$ to 7 . Equation (1) is used to calculate the removal rate of ammonia nitrogen at different adsorption times.

\section{Results and Discussion}

\subsection{XRF Result Analyses}

The chemical composition of the CGCS sample is shown in Table 1. It can be found that the main components in CGCS are metal oxides, non-metal oxides and unburned carbon. Among them, $\mathrm{SiO}_{2}$ $+\mathrm{Al}_{2} \mathrm{O}_{3}+\mathrm{Fe}_{2} \mathrm{O}_{3}+\mathrm{CaO}>92 \%$. By calculation, the molar ratio of $\mathrm{SiO}_{2} / \mathrm{Al}_{2} \mathrm{O}_{3}$ in the CGCS can be obtained as 5.2.

Table 1. Chemical composition of coal gasification crude slag (CGCS) by XRF analysis ( $w \mathrm{t} \%$ ) LOI is loss on ignition.

\begin{tabular}{cccccccccc}
\hline Parameter & $\mathrm{SiO}_{2}$ & $\mathrm{Al}_{2} \mathrm{O}_{3}$ & $\mathrm{Fe}_{2} \mathrm{O}_{3}$ & $\mathrm{CaO}$ & $\mathrm{K}_{\mathbf{2}} \mathrm{O}$ & $\mathbf{M g O}$ & $\mathrm{Na}_{2} \mathrm{O}$ & Other & $\mathrm{LOI}$ \\
\hline CGCS & 53.44 & 17.21 & 11.23 & 10.12 & 2.27 & 1.92 & 1.33 & 2.48 & 12.55 \\
\hline
\end{tabular}

\subsection{XRD Result Analysis}

\subsubsection{Influence of $\mathrm{SiO}_{2} / \mathrm{Na}_{2} \mathrm{O}$ Molar Ratio}

Figure 2a is an XRD spectrum with an initial gel composition of $5.2 \mathrm{SiO}_{2}: 1.0 \mathrm{Al}_{2} \mathrm{O}_{3}: \mathrm{xNa}_{2} \mathrm{O}: 100 \mathrm{H}_{2} \mathrm{O}$, in which the molar ratio of $\mathrm{SiO}_{2} / \mathrm{Na}_{2} \mathrm{O}$ is controlled to be $1.00-1.50$ by adjusting the amount of $\mathrm{NaOH}$ added. When the molar ratio of $\mathrm{SiO}_{2} / \mathrm{Na}_{2} \mathrm{O}$ is increased from 1.00 to 1.04, the product changes from an amorphous phase to a characteristic peak of $\mathrm{NaP}$ zeolite. As the molar ratio further increases to 1.13 , the crystallinity of the $\mathrm{NaP}$ zeolite gradually increases. Appropriate $\mathrm{OH}^{-}$groups can promote the dissolution of amorphous gel, shorten the induction period, and accelerate the growth of $\mathrm{NaP}$ zeolite crystals $[18,19]$. When the $\mathrm{SiO}_{2} / \mathrm{Na}_{2} \mathrm{O}$ molar ratio reaches 1.50 , the characteristic peak of the $\mathrm{NaP}$ zeolite is still significant, but the crystallinity is slightly decreased, which is related to the large negative charge density in the skeleton structure [20]. 

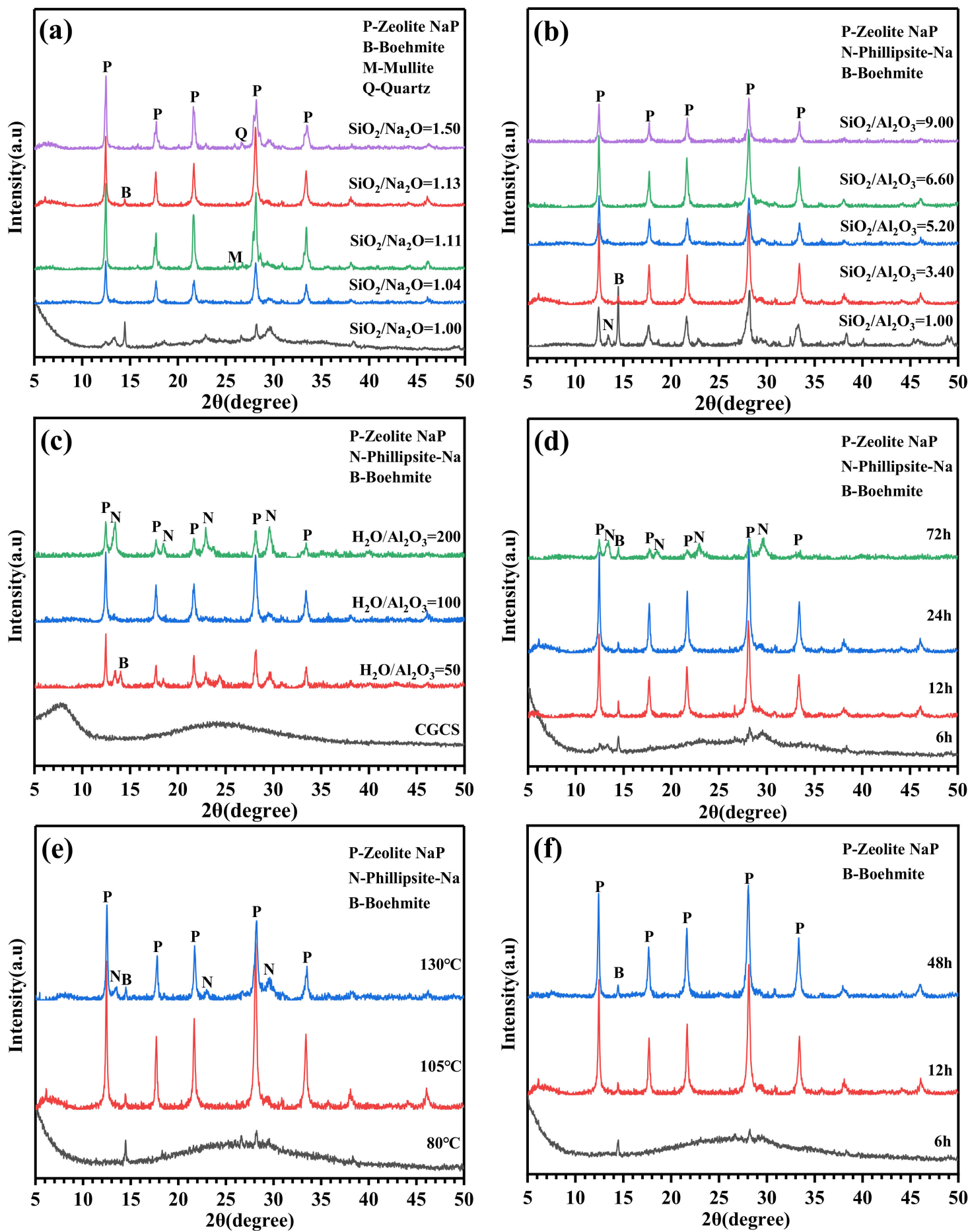

Figure 2. $\mathrm{XRD}$ patterns of $\mathrm{CGCS}$ and $\mathrm{NaP}$ zeolite synthesized under different conditions: (a) different $\mathrm{SiO}_{2} / \mathrm{Na}_{2} \mathrm{O}$ molar ratio, (b) $\mathrm{SiO}_{2} / \mathrm{Al}_{2} \mathrm{O}_{3}$ molar ratio, (c) $\mathrm{H}_{2} \mathrm{O} / \mathrm{Al}_{2} \mathrm{O}_{3}$ molar ratio, (d) aging time, (e) crystallization temperature, (f) crystallization time.

\subsubsection{Influence of $\mathrm{SiO}_{2} / \mathrm{Al}_{2} \mathrm{O}_{3}$ Molar Ratio}

Figure $2 b$ shows the XRD spectrum of the synthesized product at a molar ratio of $\mathrm{SiO}_{2} / \mathrm{Al}_{2} \mathrm{O}_{3}$ $=1.00-9.00$ Although we use the method without adding exogenous silica-alumina to prepare zeolite, the silica-alumina ratio is still an important factor in zeolite synthesis. Therefore, we still investigated the change of the final product under different silicon-aluminum ratios by adding exogenous silicon-aluminum. The initial gel composition is $x \mathrm{SiO}_{2}: 1.0 \mathrm{Al}_{2} \mathrm{O}_{3}: 5.0 \mathrm{Na}_{2} \mathrm{O}: 100 \mathrm{H}_{2} \mathrm{O}$. When 
the molar ratio of $\mathrm{SiO}_{2} / \mathrm{Al}_{2} \mathrm{O}_{3}=1.00$, the crystallinity of the $\mathrm{NaP}$ zeolite is insufficient, and the characteristic peak of the boehmite is very prominent, accompanied by a peak of Phillipsite-Na zeolite. As the molar ratio of $\mathrm{SiO}_{2} / \mathrm{Al}_{2} \mathrm{O}_{3}$ increases, the boehmite gradually weakens. Until the molar ratio was 5.20, the boehmite disappeared completely and the product tended to be converted only to NaP zeolite. At this time, we did not adjust the silica-alumina molar ratio of CGCS. Since the relative solubility of $\mathrm{Al}^{3+}$ in alkaline $\mathrm{NaOH}$ solution is lower than that of $\mathrm{Si}^{4+}$, the addition of a small amount of $\mathrm{NaOH}$ in a higher $\mathrm{SiO}_{2} / \mathrm{Al}_{2} \mathrm{O}_{3}$ molar ratio promotes the formation of $\mathrm{NaP}$ zeolite [21]. When the molar ratio reached 9.00 , the crystallinity of the $\mathrm{NaP}$ zeolite began to decrease because the amount of $\mathrm{NaOH}$ was too small to accelerate the reaction.

\subsubsection{Influence of $\mathrm{H}_{2} \mathrm{O} / \mathrm{Al}_{2} \mathrm{O}_{3}$ Molar Ratio}

Figure 2c is an XRD pattern of the synthesized products of CGCS and different $\mathrm{H}_{2} \mathrm{O} / \mathrm{Al}_{2} \mathrm{O}_{3}$ molar ratios. The initial gel composition is $5.2 \mathrm{SiO}_{2}: 1.0 \mathrm{Al}_{2} \mathrm{O}_{3}: 5.0 \mathrm{Na}_{2} \mathrm{O}: \mathrm{xH}_{2} \mathrm{O}$, where the range of $\mathrm{x}$ was adjusted by adding deionized water to 50-200. It can be seen from the XRD spectrum that there is no obvious crystalline phase in CGCS, and the materials such as silicon aluminum are mainly in the amorphous form, which further proves that the inorganic minerals are almost completely melted during the coal gasification process. When the molar ratio of $\mathrm{H}_{2} \mathrm{O} / \mathrm{Al}_{2} \mathrm{O}_{3}$ is $50, \mathrm{NaP}$ zeolite, Phillipsite-Na and sodalite can be observed in the sample, and the characteristic peak of $\mathrm{NaP}$ zeolite is prominent. When the ratio is increased to 100 , the $\mathrm{NaP}$ zeolite becomes the main crystalline phase. When the $\mathrm{H}_{2} \mathrm{O} / \mathrm{Al}_{2} \mathrm{O}_{3}$ molar ratio was further increased to 200, two crystal forms of Phillipsite-Na and $\mathrm{NaP}$ zeolite appeared in the sample. Therefore, we believe that the optimum $\mathrm{H}_{2} \mathrm{O} / \mathrm{Al}_{2} \mathrm{O}_{3}$ molar ratio of synthetic NaP zeolite is 100 .

\subsubsection{Influence of Aging Time}

Figure $2 \mathrm{~d}$ shows the XRD patterns of the synthesized products at different aging times (6-72 h). It can be seen from the XRD spectrum that when the aging time is $6 \mathrm{~h}$, CGCS basically does not react. With the aging time increasing to $12-24 \mathrm{~h}, \mathrm{NaP}$ zeolite becomes the main crystalline phase and contains only a small amount of boehmite. When the time is further increased to $72 \mathrm{~h}, \mathrm{NaP}$ zeolite will decompose and Phillipsite-Na appears. If the time is too long, it will cause amorphization or crystal transition due to its own pressure. Therefore, aging for $24 \mathrm{~h}$ can shorten the induction period and reach the maximum crystallinity.

\subsubsection{Influence of Crystallization Temperature}

Figure 2e shows the XRD patterns of the synthesized products at different hydrothermal crystallization temperatures $\left(80-130^{\circ} \mathrm{C}\right)$. It can be seen that the crystallinity below $80^{\circ} \mathrm{C}$ is insufficient and no crystalline phase appears. Because the temperature is too low, CGCS does not react with $\mathrm{NaOH}$, and it is difficult to form a new crystal phase. When the temperature is raised to $105^{\circ} \mathrm{C}$ and $130{ }^{\circ} \mathrm{C}$, the characteristic peak intensity of the $\mathrm{NaP}$ zeolite first reaches the maximum and then decreases overall, and the strength decrease is caused by the decrease of the grain size [21]. Therefore, the crystallinity of $\mathrm{NaP}$ zeolite obtained at $105^{\circ} \mathrm{C}$ is the highest.

\subsubsection{Influence of Crystallization Time}

Figure $2 \mathrm{f}$ shows the XRD patterns of the synthesized products at different hydrothermal crystallization times $(6-48 \mathrm{~h})$ at $24 \mathrm{~h}$ and $105^{\circ} \mathrm{C}$. It can be seen that when the crystallization time is $6 \mathrm{~h}$, CGCS does not react and remains amorphous. When the crystallization time is $12-48 \mathrm{~h}, \mathrm{NaP}$ zeolite becomes the main crystalline phase, because of long-term pressure of the amorphous phase, the crystallinity of zeolite decreases with time [21]. Therefore, the optimal crystallization time to reach the maximum crystallinity is $12 \mathrm{~h}$.

The above conclusions confirm that, after the CGCS and $\mathrm{NaOH}$ solution are thoroughly mixed, activated molecules of $\mathrm{SiO}_{2}$ and $\mathrm{Al}_{2} \mathrm{O}_{3}$ will be formed on the surface, and the interaction between the two will cause the active ingredients in CGCS to fall off the particle surface. When the alkaline solution 
is heated, the active components of the unit cell grid are destroyed by $\mathrm{OH}^{-}$. The $\mathrm{Si}-\mathrm{O}-\mathrm{Al}$ and $\mathrm{Si}-\mathrm{O}-\mathrm{Si}$ bonds on the surface of the particles break, and new $\mathrm{Si}(\mathrm{OH})_{5}{ }^{-}$equipotential ions are formed, causing the surface of the particles to be negatively charged. Under the action of static electricity, $\mathrm{Na}^{+}$adheres to the solid particles in the solution. In addition, the active $\mathrm{SiO}_{2}$ and $\mathrm{Al}_{2} \mathrm{O}_{3}$ react with $\mathrm{Na}^{+}$to form a hydrated sodium aluminosilicate gel and cover the surface of the CGCS, hinder the penetration and diffusion of active components, and reduce the diffusion speed of active molecules through the coating. The silicon-aluminum ratio leads to the continuous generation of crystal nuclei in the gel layer, and a complex and ordered grid-like channel structure appears, which is conducive to the diffusion of the molecules in the inner layer and accelerates the silicate condensation and crystallization. With the extension of time, crystal particles such as $\mathrm{Na}^{+}$accumulated on the surface of CGCS finally formed a stable $\mathrm{NaP}$ zeolite structure [22,23].

Based on the above results, we selected two $\mathrm{NaP}$ zeolites synthesized by adjusting the silicon-aluminum ratio $\left(\mathrm{SiO}_{2} / \mathrm{Al}_{2} \mathrm{O}_{3}=3.40\right)$ and experimental methods $\left(\mathrm{SiO}_{2} / \mathrm{Al}_{2} \mathrm{O}_{3}=5.20\right)$, and compared their performance differences under the same experimental conditions.

\subsection{SEM Results Analysis}

The morphology and particle size of the raw material CGCS and the prepared NaP zeolite were investigated by using different magnification SEM (Figure 3). The SEM micrograph of the original CGCS after thorough ground and mixed is irregularly granular and has no pore structure on the surface (Figure 3a). The NaP zeolite prepared by the green synthesis method has the characteristic structure of a rectangular prism crystal plane, which is consistent with the crystal morphology reported in the literature (Figure $3 b, d$ ) $[24,25]$. The morphology and average particle size of the samples were slightly different at different $\mathrm{SiO}_{2} / \mathrm{Al}_{2} \mathrm{O}_{3}$ molar ratios. At a lower magnification, a honeycomb crystal polymer can be observed (Figure 3c). When the magnification is increased, about 4-7 $\mu \mathrm{m}$ "cauliflower-like" aggregates (Figure 3d) can be observed. These aggregates are composed of anisotropic growth of rectangular prismatic crystals with an average diameter of less than $1 \mu \mathrm{m}$ [26].
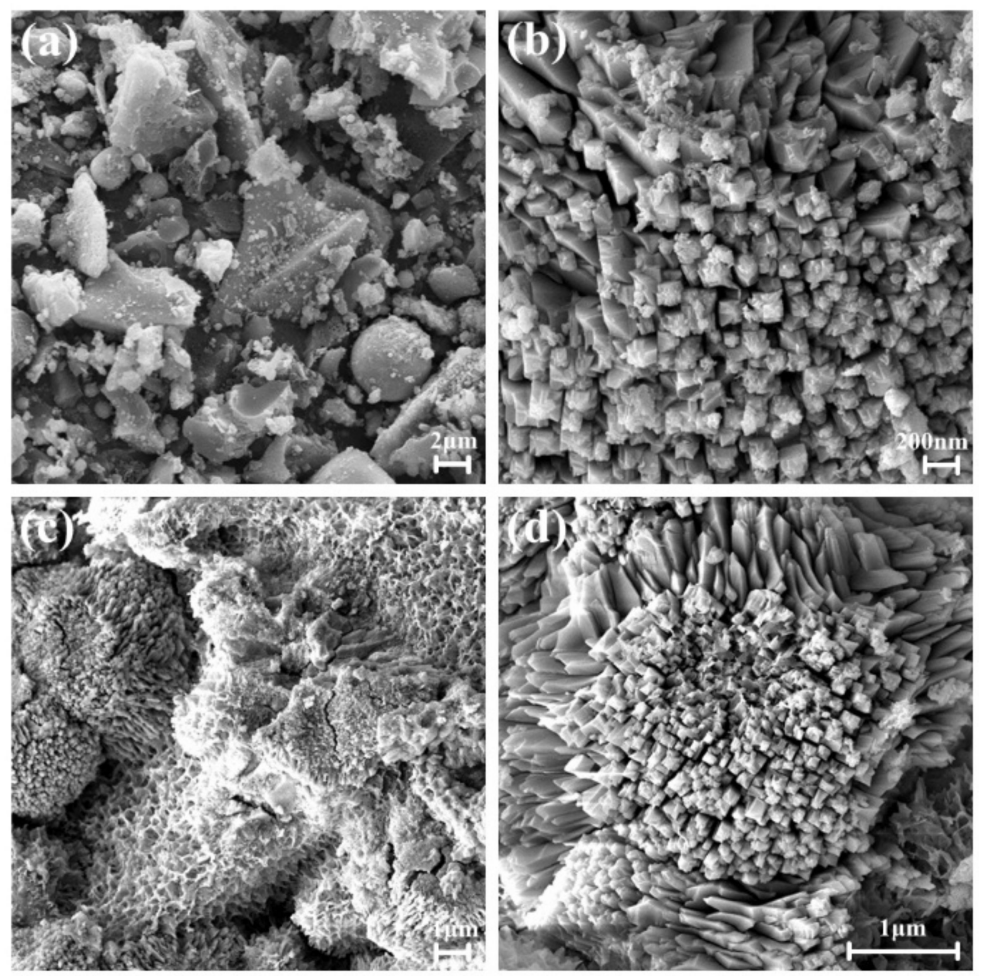

Figure 3. SEM images of CGCS and different $\mathrm{SiO}_{2} / \mathrm{Al}_{2} \mathrm{O}_{3}$ molar ratio NaP zeolites: (a) CGCS, (b) $\mathrm{SiO}_{2} / \mathrm{Al}_{2} \mathrm{O}_{3}=3.40$, (c,d) $\mathrm{SiO}_{2} / \mathrm{Al}_{2} \mathrm{O}_{3}=5.20$. 


\subsection{FT-IR Result Analysis}

Figure 4 is an FT-IR spectrum of a CGCS having a $\mathrm{SiO}_{2} / \mathrm{Al}_{2} \mathrm{O}_{3}$ molar ratio of 5.20 and 3.40 . The total vibration of the infrared spectrum of both samples is typical of $\mathrm{NaP}$ zeolite [27]. For the CGCS, the typical band near 1616 and $3444 \mathrm{~cm}^{-1}$ is assigned to the vibration of the hydroxyl groups of absorbed water [28]. In the spectrum of the $\mathrm{SiO}_{2} / \mathrm{Al}_{2} \mathrm{O}_{3}$ molar ratios of 5.20 and 3.40, the bands around 1644 and $3448 \mathrm{~cm}^{-1}$ are caused by the solid phase hydrate in the hydroxyl group or the zeolite channel [22,29]. In the raw material CGCS and NaP zeolite, the bands around 1040 and $994 \mathrm{~cm}^{-1}$ are different. The former is a typical band of silicate glasses, which belongs to $\mathrm{Si}(\mathrm{Al})-\mathrm{O}-\mathrm{Si}$ anti-symmetric stretching, and the latter is caused by the asymmetric tensile vibration of $\mathrm{YO}_{4}(\mathrm{Y}=\mathrm{Si}$ or $\mathrm{Al}$ ) tetrahedron [30]. The former shifts to the latter of the lower wavenumber due to the alternating polycondensation of Si-O and Al-O bonds, or may be due to the reaction of the glass component in the CGCS with $\mathrm{NaOH}$ to form a zeolite structure [22,31]. The bands at 728 and $462 \mathrm{~cm}^{-1}$ in the raw material CGCS is a typical mullite vibrations [23]. The bands of 740,673 and $438 \mathrm{~cm}^{-1}$ in the NaP zeolite are caused by the vibration of the internal tetrahedron or $\mathrm{YO}_{4}$. The double ring present in the $\mathrm{NaP}$ zeolite backbone can be demonstrated by a band of $603 \mathrm{~cm}^{-1}$ [32]. The vibrational peaks of the infrared spectra of the two samples matched well with the typical NaP zeolite in the literature, confirming the successful synthesis of $\mathrm{NaP}$ zeolite $[33,34]$.

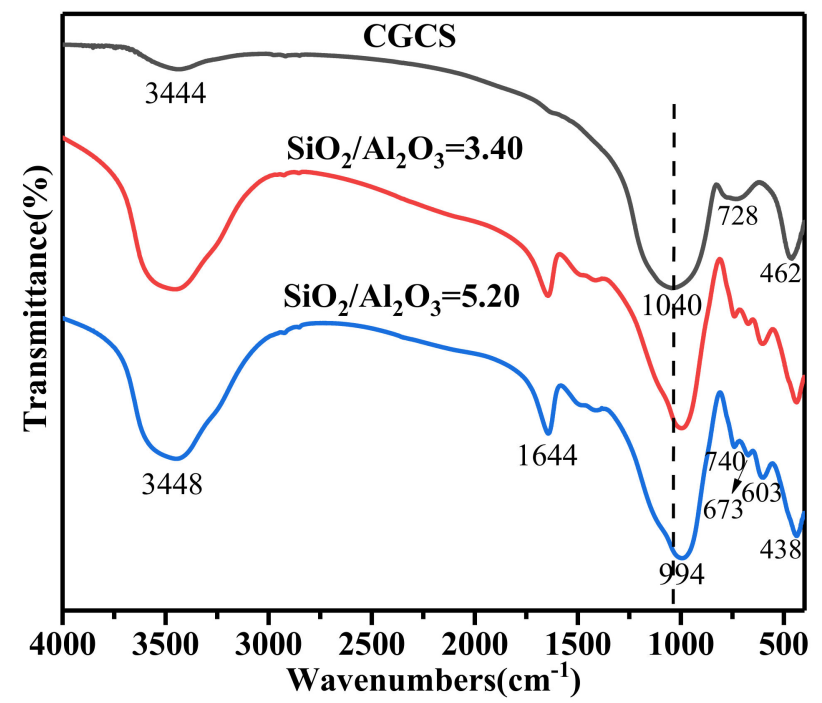

Figure 4. FT-IR spectra of CGCS and $\mathrm{NaP}$ zeolites with different $\mathrm{SiO}_{2} / \mathrm{Al}_{2} \mathrm{O}_{3}$ molar ratios.

\subsection{TG-DSC Results Analysis}

Figure $5 \mathrm{a}, \mathrm{b}$ shows the TG and DSC curves for $\mathrm{NaP}$ zeolite with different $\mathrm{SiO}_{2} / \mathrm{Al}_{2} \mathrm{O}_{3}$ molar ratio. From the TG curve, the total weight loss was $13.20 \%$ and $15.44 \%$, respectively, which is basically consistent with the shape and mass loss of the TG curve of the NaP zeolite reported in the literature [35]. In the temperature range of $20-200{ }^{\circ} \mathrm{C}$, the removal of adsorbed water is the cause of mass loss. The removal and decomposition of hydroxyl groups in $\mathrm{NaP}$ zeolite will result in a mass loss between 200 and $500{ }^{\circ} \mathrm{C}$ [34]. Two thermal effects can be clearly seen from the DSC curve of the sample, and the endothermic peaks present at around $89^{\circ} \mathrm{C}$ and $152^{\circ} \mathrm{C}$ are related to the release of water molecules in the NaP zeolite. The exothermic effects at $386^{\circ} \mathrm{C}$ and $364^{\circ} \mathrm{C}$ are independent of weight loss and are due to the conversion and decomposition of the $\mathrm{NaP}$ zeolite structure $[21,34,35]$. Therefore, the heat resistant temperatures of our synthesized $\mathrm{NaP}$ zeolites were $386^{\circ} \mathrm{C}$ and $364^{\circ} \mathrm{C}$. 

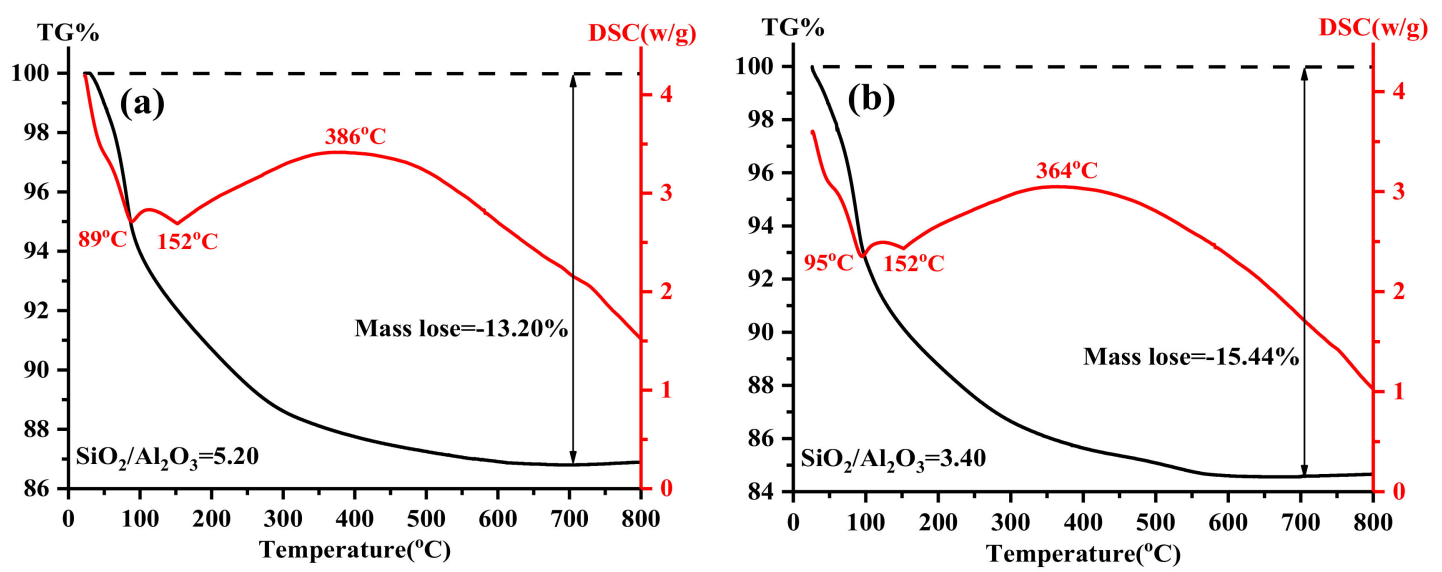

Figure 5. TG and DSC curves of different $\mathrm{SiO}_{2} / \mathrm{Al}_{2} \mathrm{O}_{3}$ molar ratio NaP zeolites (a) 5.20, (b) 3.40.

\subsection{BET Result Analysis}

Table 2 shows the results of specific surface area, external surface area, total pore volume and average pore diameter of CGCS and different $\mathrm{NaP}$ zeolites after pretreatment at $200{ }^{\circ} \mathrm{C}$. The specific surface areas of the $\mathrm{SiO}_{2} / \mathrm{Al}_{2} \mathrm{O}_{3}=5.20$ and 3.40 samples were $161.06 \mathrm{~m}^{2} / \mathrm{g}$ and $98.24 \mathrm{~m}^{2} / \mathrm{g}$, respectively, and the pore volumes were $0.0021 \mathrm{~cm}^{3} / \mathrm{g}$ and $0.0036 \mathrm{~cm}^{3} / \mathrm{g}$, respectively. The sample with a molar ratio of 5.20 has a large specific surface area and a low pore volume, which is confirmed by XRD and SEM because of the small particle size of the sample [21,32].

Table 2. Structural parameters of $\mathrm{NaP}$ zeolite with CGCS and different $\mathrm{SiO}_{2} / \mathrm{Al}_{2} \mathrm{O}_{3}$ molar ratios.

\begin{tabular}{ccccc}
\hline Sample & $\begin{array}{c}\text { Surface Area } \\
\left(\mathbf{m}^{\mathbf{2}} / \mathbf{g}\right)\end{array}$ & $\begin{array}{c}\text { External Surface } \\
\text { Area }\left(\mathbf{m}^{\mathbf{2}} / \mathbf{g}\right)\end{array}$ & $\begin{array}{c}\text { Total Pore Volume } \\
\mathbf{( \mathbf { c m } ^ { 3 } / \mathbf { g } )}\end{array}$ & $\begin{array}{c}\text { Average Aperture } \\
\mathbf{( n m )}\end{array}$ \\
\hline $\mathrm{CGCS}$ & 0.88 & 0.87 & 0.0013 & 18.05 \\
$\mathrm{SiO}_{2} / \mathrm{Al}_{2} \mathrm{O}_{3}=3.40$ & 98.24 & 88.99 & 0.0036 & 8.35 \\
$\mathrm{SiO}_{2} / \mathrm{Al}_{2} \mathrm{O}_{3}=5.20$ & 161.06 & 153.35 & 0.0021 & 5.57 \\
\hline
\end{tabular}

The isotherm of the aperture type and distribution is shown in Figure 6. The pore size distribution of the $\mathrm{NaP}$ zeolite samples synthesized at different molar ratios was calculated using the $\mathrm{N}_{2}$-DFT model. All samples exhibited a type IV isotherm with a H3 hysteresis loop (relative pressure range 0.45-0.99), which is a typical feature of mesoporous materials, where the hysteresis loop is related to the occurrence of pore condensation [36-38]. As can be seen from the $\mathrm{dV} / \mathrm{dW}$ curve, samples were present as micropores and mesopores. According to SEM morphology analysis, the zeolite mesopores are caused by intercrystalline voids and intracrystalline mesopores in the crystal. There is a certain difference between the calculated area of the external surface area and the specific surface area, which further proves that the micropores and the mesopores coexist in the obtained zeolite [39]. The experimental results show that it has good consistency with typical NaP zeolite [40,41]. 

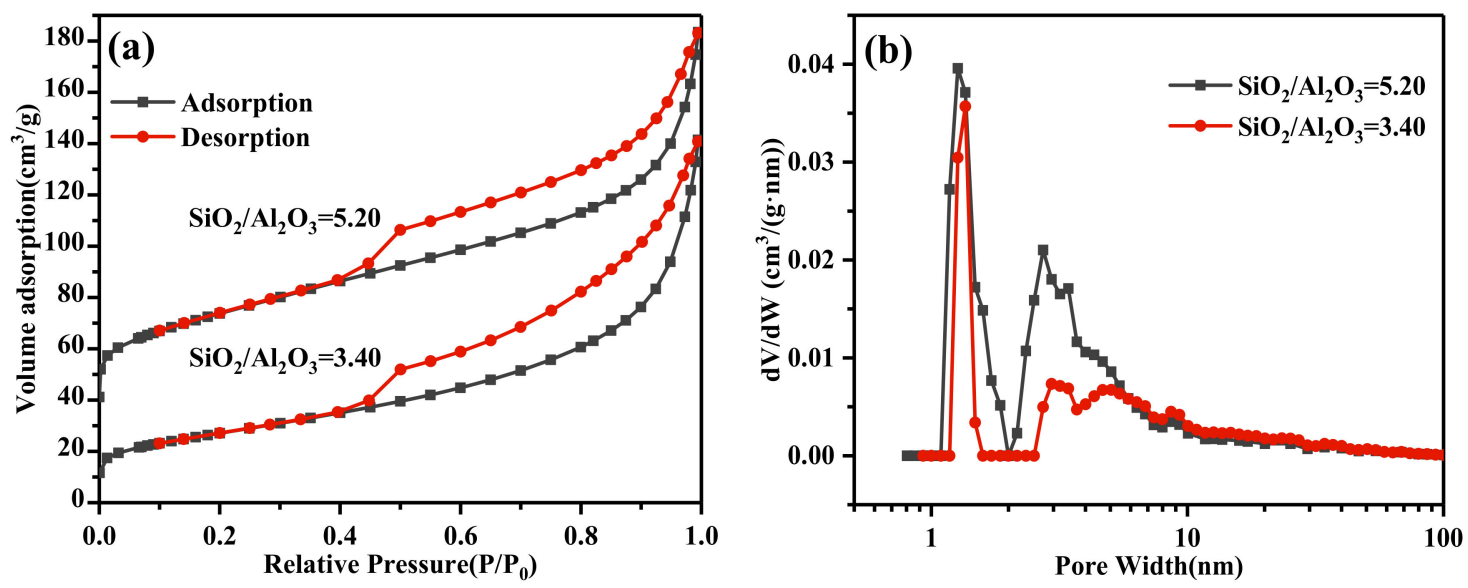

Figure 6. $\mathrm{N}_{2}$ adsorption-desorption isotherms (a) and DFT pore size distribution curve $(\mathbf{b})$ of zeolite NaP.

By comparing the results of SEM, FT-IR, TG-DSC, and BET, we found that, without adding a silicon aluminum source $\left(\mathrm{SiO}_{2} / \mathrm{Al}_{2} \mathrm{O}_{3}=5.20\right)$, the crystal morphology is more regular, the thermal stability is better, and the specific surface area is larger.

\subsection{The NaP Zeolite to Remove Ammonia Nitrogen}

The adsorption of ammonia nitrogen by $\mathrm{NaP}$ zeolite mainly depends on the ion exchange performance. The isomorphic substitution of $\mathrm{Si}$ and $\mathrm{Al}$ in the mineral structure will cause a negative charge in the zeolite channel and will be compensated by the exchange of sodium, calcium, magnesium and other ions. Secondly, the high-concentration ammonia-nitrogen solution can provide more exchange materials and form a larger concentration difference with the zeolite surface, thereby promoting the exchange of cations in $\mathrm{NaP}$ zeolite with $\mathrm{NH}_{4}{ }^{+}$in the solution. Ion exchange is the main mechanism for $\mathrm{NH}_{4}{ }^{+}$adsorption and is characterized by cation exchange capacity (CEC) [42-45].

\subsubsection{Influence of Adsorbent Dosage}

The relationship between the amount of $\mathrm{NaP}$ zeolite and the ammonia nitrogen removal rate and adsorption amount is shown in Figure 7. When the amount of zeolite was increased from $0.5 \mathrm{~g} / \mathrm{L}$ to $40 \mathrm{~g} / \mathrm{L}$, the ammonia nitrogen removal rate increased from $13.55 \%$ to $93.83 \%$, and the adsorption amount decreased from $21.11 \mathrm{mg} / \mathrm{g}$ to $2.35 \mathrm{mg} / \mathrm{g}$. It can be seen that in the wastewater with an ammonia nitrogen concentration of $100 \mathrm{mg} / \mathrm{L}$, increasing the amount of zeolite can significantly increase the removal rate of ammonia nitrogen. However, when the dosage of the adsorbent is more than $20 \mathrm{~g} / \mathrm{L}$, the ammonia nitrogen available for ion exchange decreases due to the decrease in the ammonia nitrogen concentration, and the agglomeration of the adsorbent increases, resulting in a slow increase in the ammonia nitrogen removal rate. Therefore, in the subsequent experiments, $20 \mathrm{~g} / \mathrm{L}$ was selected as the optimal dosage of adsorbent [46-48]. 


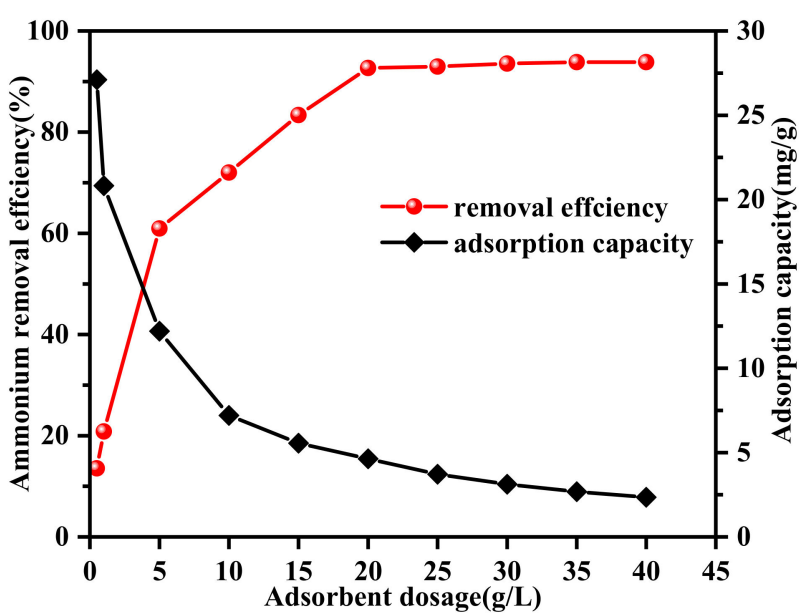

Figure 7. Effect of adsorbent dosage on Removal of ammonia nitrogen ( $\mathrm{pH}=7$; contact time: $180 \mathrm{~min})$.

\subsubsection{Influence of $\mathrm{pH}$}

The adsorption of $\mathrm{NaP}$ zeolite on ammonia nitrogen in simulated wastewater with different $\mathrm{pH}$ values is shown in Figure 8. The ammonia nitrogen removal rate is proportional to the $\mathrm{pH}$ from 3 to 7 , and inversely proportional to the $\mathrm{pH}$ from 7 to 10 . Because under acidic conditions, the ammonia nitrogen in the wastewater mainly exists in the form of $\mathrm{NH}_{4}{ }^{+}$, a large amount of $\mathrm{H}^{+}$in the wastewater competes with $\mathrm{NH}_{4}{ }^{+}$for adsorption, resulting in a decrease in the adsorption amount of ammonia nitrogen by the $\mathrm{NaP}$ zeolite. Under alkaline conditions, ammonia nitrogen in the wastewater exists in the form of molecular $\mathrm{NH}_{3}$, resulting in a decrease in adsorption capacity. Therefore, the optimum removal rate of ammonia nitrogen by synthetic $\mathrm{NaP}$ zeolite is $\mathrm{pH}=7$. This is consistent with the better selectivity of the modified zeolite reported in the literature at $\mathrm{pH}=7[49,50]$.

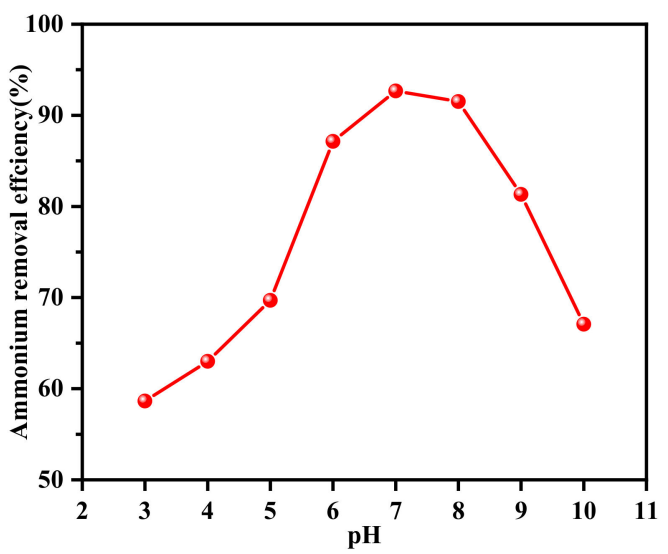

Figure 8. Effect of $\mathrm{pH}$ on ammonia nitrogen removal rate (adsorbent dosage: $20 \mathrm{~g} / \mathrm{L}$; contact time: $180 \mathrm{~min})$.

\subsubsection{Influence of Reaction Time}

According to the curve of adsorption time and removal rate in Figure 9, it can be seen that NaP zeolite is fast for adsorption of ammonia nitrogen. When the time exceeds $180 \mathrm{~min}$, the adsorption reaches equilibrium and the removal rate reaches over $92.67 \%$. At this point, zeolite adsorption $\mathrm{NH}_{4}{ }^{+}$ reaches saturation, there will be ion exchange and adsorption equilibrium in the solution, even if the contact time is extended, the removal rate cannot be significantly increased [51]. Therefore, $180 \mathrm{~min}$ was selected as the optimal adsorption time. 


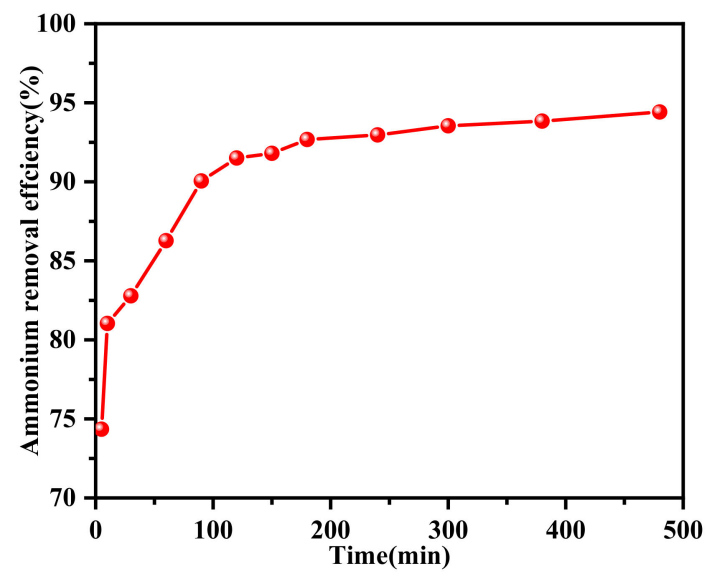

Figure 9. Effect of contact time on ammonia nitrogen removal rate (adsorbent dosage: $20 \mathrm{~g} / \mathrm{L} ; \mathrm{pH}=7$ ).

Through the analysis of the above results, we can conclude that the dosage of $\mathrm{NaP}$ zeolite is directly proportional to the removal rate, and has the characteristics of fast adsorption and slow equilibrium. The $\mathrm{pH}$ value of the solution has a great effect on the removal of ammonia nitrogen by zeolite, and the removal effect is best under neutral conditions. The best adsorption parameters were: zeolite dosage of $20 \mathrm{~g} / \mathrm{L}$, solution $\mathrm{pH}=7$, and adsorption time of $180 \mathrm{~min}$.

\section{Conclusions}

$\mathrm{NaP}$ zeolite with good physical properties can be synthesized by adding a small amount of $\mathrm{NaOH}$ and deionized water to the discarded CGCS. Adjust the molar ratio to $\mathrm{SiO}_{2}: \mathrm{Al}_{2} \mathrm{O}_{3}: \mathrm{Na}_{2} \mathrm{O}: \mathrm{H}_{2} \mathrm{O}=$ 5.2:1.0:5.0:100. This process does not require additional silicon source aluminum source and template agent, and does not require high temperature calcination. After aging for $24 \mathrm{~h}$ and crystallization at $105^{\circ} \mathrm{C}$ for $12 \mathrm{~h}, \mathrm{NaP}$ zeolite with high crystallinity and regular morphology and a specific surface area of $161.06 \mathrm{~m}^{2} / \mathrm{g}$ can be obtained. The process has the characteristics of simple operation, low energy consumption, low cost, small secondary pollution, and easy industrialization. It is a resource utilization method of CGCS, and the water used in the process can be treated and recycled, which can basically achieve "zero discharge". The synthetic NaP zeolite has a good removal effect on ammonia nitrogen in industrial wastewater, the best removal rate is $92.67 \%$, and the adsorption amount is $4.63 \mathrm{mg} / \mathrm{g}$. Although the adsorption amount is not large, it has a large application prospect because of its simple preparation and low cost. $\mathrm{Na}^{+}$plays an important role in the formation of $\mathrm{NaP}$ zeolite crystals, and at the same time it can ion-exchange with $\mathrm{NH}_{4}{ }^{+}$, which is beneficial to the removal of ammonia nitrogen in wastewater.

Our work proposes a new way to solve the problems of large-scale accumulation, difficulty of utilization, huge environmental pressure, and high transportation cost of CGCS. The environmental functional materials prepared by CGCS can be applied to wastewater treatment in the industrial production process, which reduces the cost of the enterprise, realizes the resource utilization of waste, and achieves the purpose of "treating waste by waste".

Author Contributions: Conceptualization, Y.M.; Investigation, W.J. and L.L.; Methodology, W.J.; Resources, W.J. and Y.M.; Supervision, Y.S. and Y.L.; Visualization, S.Z. and N.F.; Writing - original draft, P.Z. and X.Z.; Writing review \& editing, W.J. and S.Z. All authors have read and agreed to the published version of the manuscript.

Funding: This research was funded by The National Science Foundation of China (No. 21663019) and The East-West Cooperation Project of Ningxia Key R \& D Plan (2019BFH02014).

Conflicts of Interest: The authors declare that there are no conflicts of interest. 


\section{References}

1. Andrews, R.; Rubel, A.; Groppo, J.; Marrs, B. Advanced Gasification by-Product Utilization; Final Technical Report; University of Kentucky Center for Applied Energy Research: Lexington, KY, USA, 2006.

2. Zhao, X.; Zeng, C.; Mao, Y.; Li, W.; Peng, Y. The surface characteristics and reactivity of residual carbon in coal gasification slag. Energy Fuels 2009, 24, 91-94. [CrossRef]

3. Tang, Y.; Guo, X.; Xie, Q.; Finkelman, R.B.; Han, S. Petrological characteristics and trace element partitioning of gasification residues from slagging entrained-flow gasifiers in Ningdong, China. Energy Fuels 2018, 32, 3052-3067. [CrossRef]

4. Ge, J.C.; Yoon, S.K.; Choi, N.J. Application of fly ash as an adsorbent for removal of air and water pollutants. Appl. Sci. 2018, 8, 1116. [CrossRef]

5. Wu, S.; Huang, S.; Ji, L.; Wu, Y. Structure characteristics and gasification activity of residual carbon from entrained-flow coal gasification slag. Fuel 2014, 122, 67-75. [CrossRef]

6. Jun, Y.; Yoon, S.; Oh, J.E. A comparison study for chloride-binding capacity between alkali-activated fly ash and slag in the use of seawater. Appl. Sci. 2017, 7, 971. [CrossRef]

7. Yao, Z.T.; Ji, X.S.; Sarker, P.K.; Tang, J.H. A comprehensive review on the applications of coal fly ash. Earth Sci. Rev. 2015, 141, 105-121. [CrossRef]

8. Asl, S.M.H.; Ghadi, A.; Baei, M.S.; Javadian, H. Porous catalysts fabricated from coal fly ash as cost-effective alternatives for industrial applications: A review. Fuel 2018, 217, 320-342.

9. Liu, S.; Qi, C.; Jiang, Z.; Zhang, Y.; Niu, M.; Li, Y. Mineralogy and geochemistry of ash and slag from coal gasification in China: A review. Int. Geol. Rev. 2018, 60, 717-735. [CrossRef]

10. Li, C.C.; Qiao, X.C.; Yu, J.G. Large surface area MCM-41 prepared from acid leaching residue of coal gasification slag. Mater. Lett. 2016, 167, 246-249. [CrossRef]

11. Xu, Y.; Chai, X. Characterization of coal gasification slag-based activated carbon and its potential application in lead removal. Environ. Technol. 2018, 39, 382-391. [CrossRef]

12. Gu, Y.Y.; Qiao, X.C. A carbon silica composite prepared from water slurry coal gasification slag. Microporous Mesoporous Mater. 2019, 276, 303-307. [CrossRef]

13. Liu, S.; Chen, X.; Ai, W.; Wei, C. A new method to prepare mesoporous silica from coal gasification fine slag and its application in methylene blue adsorption. J. Cleaner Prod. 2019, 212, 1062-1071. [CrossRef]

14. Ji, Q.; Tabassum, S.; Hena, S.; Silva, C.G. A review on the coal gasification wastewater treatment technologies: Past, present and future outlook. J. Cleaner Prod. 2016, 126, 38-55. [CrossRef]

15. Tang, Y.; Wang, Y.; Huan, B.; Guo, X. Leachability of hazardous trace elements from entrained-flow coal gasification residues in Ningdong, China. Energy Fuels 2017, 31, 9703-9716. [CrossRef]

16. Tang, Y.; Guo, X.; Pan, X.; Finkelman, R.; Wang, Y. Changes and Distribution of Modes of Occurrence of Seventeen Potentially-Hazardous Trace Elements during Entrained Flow Gasification of Coals from Ningdong, China. Minerals 2018, 8, 202. [CrossRef]

17. Ministry of Ecology and Environment of People's Republic of China. Water Quality-Determination of Ammonia Nitrogen-Nessler's Reagent Spectrophotometry; Chinese standard HJ 535-2009; Ministry of Ecology and Environment of People's Republic of China: Pekin, China, 2010.

18. Ali, I.O.; Hassan, A.M.; Shaaban, S.M.; Soliman, K.S. Synthesis and characterization of ZSM-5 zeolite from rice husk ash and their adsorption of $\mathrm{Pb}^{2+}$ onto unmodified and surfactant-modified zeolite. Sep. Purif. Technol. 2011, 83, 38-44.

19. Kim, S.D.; Noh, S.H.; Park, J.W.; Kim, W.J. Organic-free synthesis of ZSM-5 with narrow crystal size distribution using two-step temperature process. Microporous Mesoporous Mater. 2006, 92, 181-188. [CrossRef]

20. Kim, S.D.; Noh, S.H.; Seong, K.H.; Kim, W.J. Compositional and kinetic study on the rapid crystallization of ZSM-5 in the absence of organic template under stirring. Microporous Mesoporous Mater. 2004, 72, 185-192. [CrossRef]

21. Ali, I.O.; El-Sheikh, S.M.; Salama, T.M.; Bakr, M.F. Controllable synthesis of NaP zeolite and its application in calcium adsorption. Sci. China Mater. 2015, 58, 621-633. [CrossRef]

22. Liu, Y.; Yan, C.; Zhang, Z.; Wang, H.; Zhou, S.; Zhou, W. A comparative study on fly ash, geopolymer and faujasite block for Pb removal from aqueous solution. Fuel 2016, 185, 181-189. [CrossRef]

23. Zhang, Z.; Wang, H.; Provis, J.L. Quantitative study of the reactivity of fly ash in geopolymerization by FTIR. J. Sustain. Cem. Based Mater. 2012, 1, 154-166. [CrossRef] 
24. Cardoso, A.M.; Paprocki, A.; Ferret, L.S.; Azevedo, C.M. Synthesis of zeolite Na-P1 under mild conditions using Brazilian coal fly ash and its application in wastewater treatment. Fuel 2015, 139, 59-67. [CrossRef]

25. Cardoso, A.M.; Horn, M.B.; Ferret, L.S.; Azevedo, C.M. Integrated synthesis of zeolites 4A and Na-P1 using coal fly ash for application in the formulation of detergents and swine wastewater treatment. J. Hazard. Mater. 2015, 287, 69-77. [CrossRef] [PubMed]

26. Sánchez-Hernández, R.; López-Delgado, A.; Padilla, I.; Galindo, R. One-step synthesis of NaP1, SOD and ANA from a hazardous aluminum solid waste. Microporous Mesoporous Mater. 2016, 226, 267-277. [CrossRef]

27. Albert, B.R.; Cheetham, A.K.; Stuart, J.A.; Adams, C.J. Investigations on P zeolites: Synthesis, characterisation, and structure of highly crystalline low-silica NaP. Microporous Mesoporous Mater. 1998, 21, 133-142. [CrossRef]

28. Liu, Y.; Yan, C.; Qiu, X.; Li, D.; Wang, H. Preparation of faujasite block from fly ash-based geopolymer via in-situ hydrothermal method. J. Taiwan Inst. Chem. Eng. 2016, 59, 433-439. [CrossRef]

29. Rayalu, S.S.; Udhoji, J.S.; Meshram, S.U.; Naidu, R.R. Estimation of crystallinity in fly ash-based zeolite-A using XRD and IR spectroscopy. Curr. Sci. 2005, 89, 2147-2151.

30. Yao, Y.; Sun, H. A novel silica alumina-based backfill material composed of coal refuse and fly ash. J. Hazard. Mater. 2012, 213, 71-82. [CrossRef]

31. Stevens, R.W., Jr.; Siriwardane, R.V.; Logan, J. In situ Fourier transform infrared (FT-IR) investigation of $\mathrm{CO}_{2}$ adsorption onto zeolite materials. Energy Fuels 2008, 22, 3070-3079. [CrossRef]

32. Sharma, P.; Song, J.S.; Han, M.H.; Cho, C.H. GIS-NaP1 zeolite microspheres as potential water adsorption material: Influence of initial silica concentration on adsorptive and physical/topological properties. Sci. Rep. 2016, 6, 22734. [CrossRef]

33. Bohra, S.; Kundu, D.; Naskar, M.K. Synthesis of cashew nut-like zeolite NaP powders using agro-waste material as silica source. Mater. Lett. 2013, 106, 182-185. [CrossRef]

34. Huo, Z.; Xu, X.; Lü, Z.; Song, J.; He, M. Synthesis of zeolite NaP with controllable morphologies. Microporous Mesoporous Mater. 2012, 158, 137-140. [CrossRef]

35. Liu, Y.; Yan, C.; Zhao, J.; Zhang, Z.; Wang, H. Synthesis of zeolite P1 from fly ash under solvent-free conditions for ammonium removal from water. J. Cleaner Prod. 2018, 202, 11-22. [CrossRef]

36. Koshy, N.; Jha, B.; Kadali, S.; Singh, D.N. Synthesis and characterization of Ca and Na zeolites (non-pozzolanic materials) obtained from fly Ash-Ca $(\mathrm{OH})_{2}$ interaction. Mater. Perform. Charact. 2015, 4, 87-102.

37. Sing, K.S. Reporting physisorption data for gas/solid systems with special reference to the determination of surface area and porosity (Recommendations 1984). Pure Appl. Chem. 1985, 57, 603-619. [CrossRef]

38. Bandura, L.; Franus, M.; Józefaciuk, G.; Franus, W. Synthetic zeolites from fly ash as effective mineral sorbents for land-based petroleum spills cleanup. Fuel 2015, 147, 100-107. [CrossRef]

39. Zhou, C.; Gao, Q.; Luo, W.; Zhou, Q.; Wang, H. Preparation, characterization and adsorption evaluation of spherical mesoporous Al-MCM-41 from coal fly ash. J. Taiwan Inst. Chem. Eng. 2015, 52, 147-157. [CrossRef]

40. Aldahri, T.; Behin, J.; Kazemian, H.; Rohani, S. Synthesis of zeolite Na-P from coal fly ash by thermo-sonochemical treatment. Fuel 2016, 182, 494-501. [CrossRef]

41. Majchrzak-Kuceba, I.; Nowak, W. A thermogravimetric study of the adsorption of $\mathrm{CO}_{2}$ on zeolites synthesized from fly ash. Thermochim. Acta 2005, 437, 67-74. [CrossRef]

42. Nasir, N.; Daud, Z.; Abd Kadir, A.; Latiff, A.A.A.; Ahmad, B.; Suhani, N.; Halim, A.A. Removal of ammonia nitrogen from rubber industry wastewater using zeolite as adsorbent. Malays. J. Fundam. Appl. Sci. 2019, 15, 862-866.

43. Huo, H.; Lin, H.; Dong, Y.; Cheng, H.; Wang, H.; Cao, L. Ammonia-nitrogen and phosphates sorption from simulated reclaimed waters by modified clinoptilolite. J. Hazard. Mater. 2012, 229, 292-297. [CrossRef] [PubMed]

44. Wang, H.; Gui, H.; Yang, W.; Li, D.; Tan, W.; Yang, M.; Barrow, C.J. Ammonia nitrogen removal from aqueous solution using functionalized zeolite columns. Desalin. Water Treat. 2014, 52, 753-758. [CrossRef]

45. Kizito, S.; Wu, S.; Kirui, W.K.; Lei, M.; Lu, Q.; Bah, H.; Dong, R. Evaluation of slow pyrolyzed wood and rice husks biochar for adsorption of ammonium nitrogen from piggery manure anaerobic digestate slurry. Sci. Total Environ. 2015, 505, 102-112. [CrossRef] [PubMed]

46. Zhang, M.; Zhang, H.; Xu, D.; Han, L.; Niu, D. Removal of ammonium from aqueous solutions using zeolite synthesized from fly ash by a fusion method. Desalination 2011, 271, 111-121. [CrossRef]

47. Arslan, A.; Veli, S. Zeolite $13 \mathrm{X}$ for adsorption of ammonium ions from aqueous solutions and hen slaughterhouse wastewaters. J. Taiwan Inst. Chem. Eng. 2012, 43, 393-398. [CrossRef] 
48. Behin, J.; Bukhari, S.S.; Kazemian, H.; Rohani, S. Developing a zero liquid discharge process for zeolitization of coal fly ash to synthetic NaP zeolite. Fuel 2016, 171, 195-202. [CrossRef]

49. He, Y.; Lin, H.; Dong, Y.; Liu, Q.; Wang, L. Simultaneous removal of ammonium and phosphate by alkaline-activated and lanthanum-impregnated zeolite. Chemosphere 2016, 164, 387-395. [CrossRef]

50. Thornton, A.; Pearce, P.; Parsons, S.A. Ammonium removal from solution using ion exchange on to MesoLite, an equilibrium study. J. Hazard. Mater. 2007, 147, 883-889. [CrossRef]

51. Saltalı, K.; Sarı, A.; Aydın, M. Removal of ammonium ion from aqueous solution by natural Turkish (Yıldızeli) zeolite for environmental quality. J. Hazard. Mater. 2007, 141, 258-263. [CrossRef]

(C) 2020 by the authors. Licensee MDPI, Basel, Switzerland. This article is an open access article distributed under the terms and conditions of the Creative Commons Attribution (CC BY) license (http://creativecommons.org/licenses/by/4.0/). 